the presence of man-produced radionuclides in the environment. For the general public it is important to get the message across that today there is a sound basis for proliferation of nuclear power; there are no insurmountable scientific problems in the disposal of waste products to the sea or land. There are risks associated with all technologies, but there are also considerable advantages - hence a balance has to be achieved very soon.

Lambert provides the scientific framework upon which evaluations and judgements can be made by those with limited knowledge of nuclear matters, by contrast to Gould and Goldman who present areas of concern which are not based upon proven scientific evidence, but rather the extrapolation of controversial findings well beyond any reasonable level of acceptance. Nevertheless, there are some facts in the fiction - but of course this is common to many areas of controversy, especially when evaluating man's impact on the environment in relation to technological and social evolution.

In the short to medium term, there are no viable alternatives to the generation of electricity by nuclear means, neither are there any serious technological difficulties involved in the process. To expect a noeffect relation between technology, man and the environment is not reasonable. Overall, the benefits of accepted technology outweigh the disadvantages. It is to be hoped that the nuclear debate will become more open and informed so that the advantages and disadvantages can be properly evaluated.

E. I. Hamilton is an environmental consultant and Director of Phoenix Research Laboratory, Penglebe, Milton Abbot, Dunterton, Tavistock, Devon PL19 OQJ, UK.

\title{
Cold fusion and other matters
}

FOR many years, trenchant observations on the affairs of science in the United States have been provided by the legendary Grant Swinger, director of the mythical Center for the Absorption of Federal Funds. Here Dr Swinger converses with Daniel S. Greenberg of Science \& Government Report, on 1 June 1989.

$Q$. How do you see the Bush Administration shaping up in the science-policy area?

$A$. That's best judged after they take office.

$Q$. They've been in for over four months.

A. Four months? As long as that. It is difficult to keep track of time in the absence of activity. But I can say that the general atmosphere in the country and in Washington is favourable to innovative approaches.

$Q$. Example.

$A$. Cold fusion. An exemplary case in the best tradition of the Center for the Absorption of Federal Funds. If I have any concerns, they're directed at my own institution for not doing it first. Think of it: no publication, just a press conference. And they get $\$ 5$ million from the Utah legislature. Jim Fletcher, the ex-chief of NASA, joins up with them, and over a hundred corporations line up and plead for a piece of the action. It's on the covers of Time and Newsweek, and Congress invites them in to talk about $\$ 25$ million. And if there's anything there, no one can find it! This is a triumph. We've worked for years to get the Congress, the press, and the public to this stage.

$Q$. Very unusual events.

$A$. Actually, we've pulled this off in medical research many, many times. There's almost nothing that hasn't been reported cured or on the brink of a cure. But this has hardly ever been done in the physical sciences. The closest thing now going is the search for extra-terrestrial life, but that's never got beyond a small scale.

$Q$. On cold fusion, there was some scepticism at the outset.

$A$. That's bound to happen when you try to undercut other researchers in a field. The main opposition came from the hotfusion tokamak crowd - very innovative people when it comes to protecting their territory. After the first report about cold fusion came out, they advised Congress not to put any money into it until it's proven.

$Q$. That seems to be a prudent approach.

$A$. Prudent to wait until it's proven? Hot fusion has been running for 30 years without anything proven. And they're now at $\$ 400$ million a year.

$Q$. They feared competition?

$A$. It was potentially very embarrassing, very threatening, this tabletop stuff for a mere $\$ 100,000$. But do you know the worst of it?

\section{$Q$. What?}

$A$. The worst of it was that these fusion researchers shouted that they used their own money. As far as I'm concerned, that's unforgivable. They're cannibals. Whether or not cold fusion works is a minor matter. But using their own money. The precedent, I mean -

$Q$. Please, calm down, Dr Swinger. What are you planning at your centre?

$A$. We have a number of activities. Inspired by recent events, we're working on an alternative to the superconducting super collider.

$Q$. What will that be?

$A$. Table-top particle acceleration. Our motto is: "Fifty-three inches is better than 53 miles. One in each state." The politics are sound, even better than our old proposal for a transcontinental linear accelerator that would run across a dozen or so states. That would have brought in 24 senators and maybe a hundred congressmen.

$Q$. Is table-top particle accleration feasible?

$A$. We're going about this in the right way to find out. First, we're setting up a task force to plan a workshop preliminary to holding a conference. Next comes a call for papers. Then we'll circulate the proceedings for comment and issue a draft report. A small conference will follow to oversee preparation of the final report. This is the standard way of approaching these things. We'd be criticized if we went about it in any other fashion.

$Q$. If I may say so, table-top particle acceleration does seem too far-fetched to warrant all that effort.

$A$. This is an open-ended business. Opportunities can be anyplace. A lot of people thought Star Wars was too farfetched to get a nickel. But there it is. And what about the manned space station?

$Q$. What about it?

$A$. It's terrific. No one knows how much it will cost or what it's supposed to do. But it's going ahead. That's an ideal project, in our view.

$Q$. What do you foresee as new growth areas?

$A$. There's a lot of talent out there working up new possibilities. We were worried about the Department of Energy losing that old entrepreneurial spirit, but they reassured us all by cooking up the mapping of the human genome. It's not really their business, but that lit a fire under NIH and they've moved into the genome trade. Of course, it also took a little nudging about the Japanese rushing into this before Congress came across with the money. But bless the Japanese. They've arrived just as the steam was going out of the warnings about how we have to beat the Russians in this or that. What would we do without the Japanese? Without them, superconductivity research would be in the poor house.

$Q$. What else do you see ahead for growth in science and technology?

$A$. The greenhouse effect is bound to be a gold mine. And we see a lot of forthcoming activity devoted to agonizing over scientific priorities: conferences, white papers, congressional hearings, and all the usual stuff. It's a small industry all by itself.

$Q$. In this period of economic challenge, well-chosen scientific priorities are very important for making the best use of valuable scarce resources, aren't they?

A. What?

$Q$. I was noting the importance of wellchosen scientific priorities.

A. I see. Excuse me, I'm late for a meeting.

The Grant Swinger Papers, 2nd edn. Science \& Government Report, 6226 Northwest Station, Washington, DC 20015: 1990. Pp. 40. \$8.95 (\$10.95 overseas orders). 